\title{
Pneumopancreatogram after injection therapy for bleeding duodenal ulcer
}

A 50-year-old woman was admitted with a history of melena in the last $24 \mathrm{~h}$. She reported having suffered intermittent mild mid-epigastric pain, postprandial nausea, and bilious emesis during the past 3 months. She was taking nonsteroidal anti-inflammatory drugs up to $1200 \mathrm{mg}$ per day. On examination she was pale, afebrile, with a regular heart rate at 100 beats/min and a blood pressure of $110 / 60 \mathrm{~mm} \mathrm{Hg}$. She had abdominal tenderness with no signs of guarding. Laboratory data showed the hemoglobin concentration at $7 \mathrm{~g} / \mathrm{dL}$ and leukocytosis $\left(23 \times 10^{9} / \mathrm{L}\right)$. Plain abdominal and chest radiographs were normal. After stabilization, gastroscopy revealed a large duodenal ulcer covered by a nonremovable blood clot and oozing that was effectively controlled by injection therapy with ethanolamine. After endoscopy the patient was in severe pain, and a CT scan of the abdomen revealed pneumopancreas ( $\bullet$ Fig. 1). She responded promptly to conservative medical therapy. The follow-up CT 14 days later showed a marked reduction of the pneumopancreas, with a thin, air-filled fistulous tract between the gastric lumen and the pancreatic duct ( $\nabla$ Fig. 2). Complete healing of the ulcer was achieved with antisecretory therapy. The patient presented 3 months later with jaundice as a result of stricture of the distal common bile duct. Surgical hepaticojejunostomy was performed and she recovered uneventfully and is cholangitis-free, 1 year after the operation.

Pancreatic gas is a rare finding, usually complicating phlegmonous pancreatitis or fistulization from pancreatic pseudocyst rupture [1]. Fistulization into the main pancreatic duct as a complication of penetrating ulcer should be also considered [2]. In our patient, despite recurrent abdominal pain the diagnosis remained elusive until pneumopancreas occurred after gastroscopy, because of the considerable volume of air entering the pancreatic duct during endoscopic air insufflation. The majority of these fistulas heal with a conservative approach. However, surgery may be eventually required in patients with biliary sequelae, as in our case.

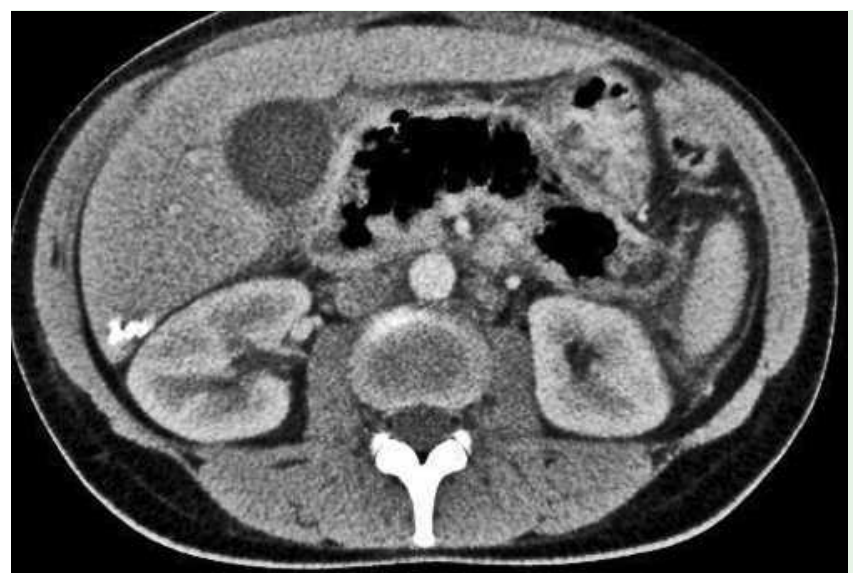

Fig. 1 Contrast-enhanced $\mathrm{CT}$ scan of the abdomen revealed a markedly distended gas-filled pancreatic duct, with no inflammatory changes in the pancreas, peripancreatic collections, or pneumoperitoneum.

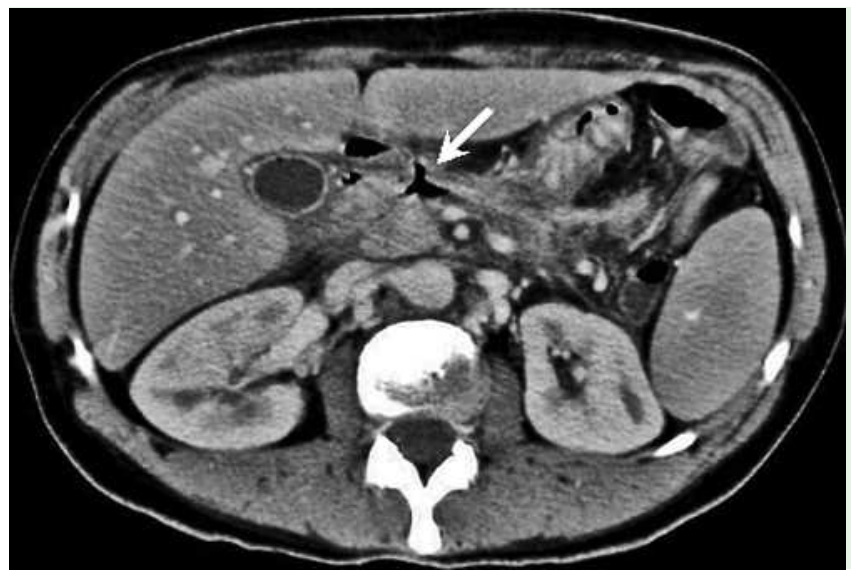

Fig. 2 Follow-up CT 14 days later showing a marked reduction of pneumopancreas and loss of fascial planes, with a thin, air-filled sinus tract (white arrow) between the adjacent bowel wall and the head of the pancreas.

Endoscopy_UCTN_Code_CPL_1AH_2AC

\section{E. Saperas ${ }^{1}$, A. Miranda ${ }^{2}$, J. R. Armen- gol $^{1}$, J. R. Malagelada ${ }^{1}$}

Department of Gastroenterology, University Hospital Vall d'Hebron, Barcelona, Spain

2 Department of Radiology, University Hospital Vall d'Hebron, Barcelona, Spain

\section{References}

1 Alexander ES, Clark RA, Federle MP. Pancreatic gas: indication of pancreatic fistula. AJR Am J Roentgenol 1982; 139: 1089-1093

2 Hughes JJ, Blunck CE. CT demonstration of gastropancreatic fistula due to penetrating gastric ulcer. J Comput Assist Tomogr 1987; 11: $709-711$
Bibliography DOI 10.1055/s-2007-966618

Endoscopy 2007; 39: E277

(c) Georg Thieme Verlag KG Stuttgart · New York . ISSN 0013-726X

Corresponding author

\section{E. Saperas, MD}

Department of Gastroenterology

University Hospital Vall d'Hebron po Vall d'Hebron 119-129 08035 Barcelona

Spain

Fax: +34-93-4281883

esaperas@vhebron.net 